\title{
低温对棉纤维比强度形成的生理机制影响
}

\author{
蒋光华 孟亚利 陈兵林 市海云 周治国 *
}

（南京农业大学,农业部作物生长调控重点开放实验室, 南京 210095）

\begin{abstract}
摘 要 通过设置播期试验使棉纤维加厚发育过程( 跉龄 25 50 d) 处于不同的温度条件下, 研究低温对棉花纤维 比强度形成的内在生理机制影响, 为采取调控措施解决目前棉花 (Gossypium) 生产中存在的晚熟劣质问题提供理论 依据。两年试验结果表明: 棉纤维加厚发育期 $24.0{ }^{\circ} \mathrm{C}$ 左右的日均温是高强纤维形成的最佳温度, 其内在生理机制 表现为棉纤维蔗糖合成酶活性最高, $\beta-1,3$-葡聚糖酶活性最低, 纤维素的累积量和累积速率均明显高于其它低温条 件, 纤维超分子结构取向参数角较小, 处于优化状态, 最终表现为纤维比强度亦最大; 低于 $21.0{ }^{\circ} \mathrm{C}$ 时即对棉纤维加 厚发育相关酶活性产生明显影响, 纤维比强度降低。当温度降到 $15.0{ }^{\circ} \mathrm{C}$ 左右时, 棉纤维蔗糖合成酶活性显著降 低, 而 $\beta-1,3$-葡聚糖酶活性显著升高, 同时纤维素累积量和累积速率均显著降低, 纤维超分子结构取向参数角明显 宽化, 棉纤维不能正常发育, 不利于高强纤维的形成( 铃重仅为 $3.22 \mathrm{~g}$, 纤维比强度仅为 $15.73 \mathrm{cN} \cdot \mathrm{tex}^{-1}$ )。
\end{abstract}

关键词 低温 棉纤维加厚发育 蔗糖合成酶 $\beta-1,3$-葡聚糖酶 纤维素含量 超分子结构 纤维比强度

\section{EFFECTS OF LOW TEMPERATURE ON PHYSIOLOGICAL MECHANISMS OF COTTON FIBER STRENGTH FORMING PROCESS}

\author{
JIANG Guang-Hua MENG Ya-Li CHEN Bing-Lin BIAN Hai-Yun and ZHOU Zhi-Guo* \\ ( Key Laboratory of Crop Growth Regulation, Ministry of Agriculture, Nanjing Agricultural University, Nanjing 210095, China)
}

\begin{abstract}
It is believed that the thickening process of fiber in cotton is affected by low temperature as late seeding often produces poor quality cotton. Effects of temperature on the physiological mechanisms of cotton fiber strength forming processes were studied to determine whether low temperature was responsible for the bad quality of late maturing cotton by regulating temperature during growth. The results of a 2-year experiment showed that mean daily temperature of $24.0{ }^{\circ} \mathrm{C}$ during the boll stage between 25 to 50 days formed highstrength cotton fiber. Cotton fiber sucrose synthetase activity was the highest, $\beta$-1, 3-glucanase activity was the lowest, and cellulose accumulation and accumulation rates were the highest at this temperature. When mean daily temperature was lower than $21.0{ }^{\circ} \mathrm{C}$, enzyme activity related to cotton fiber thickening development was reduced resulting in lower fiber strength. When mean daily temperature were around $15.0{ }^{\circ} \mathrm{C}$, the fiber sucrose synthetase activity evidently fell, $\beta-1,3$-glucanase activity increased, and quantity of cellulose accumulated and accumulation rate evidently declined. In this case, cotton fiber development was abnormal, and boll weight was only $3.22 \mathrm{~g}$, and fiber strength only $15.73 \mathrm{cN} \bullet \operatorname{tex}^{-1}$.
\end{abstract}

Key words Low temperature, Cotton fiber thickening development, Sucrose synthetase, $\beta-1$, 3-glucanase, Cellulose content, Fiber strength

棉花 (Gossypium) 属于喜温型、具有无限开花结 铃习性作物, 温度是影响棉铃发育的首要生态因子 (黄骏麒, 1998)。近年来, 农业结构调整使多熟种植 棉花面积扩大, 在单位面积周年增产大宗农产品的 同时, 棉花因受生长季节热量资源、后期气温下降和 霜期的影响, 带来了棉花普遍晚发晚熟劣质问题(刘 毓湘, 1995)。如何充分利用有限的温光资源, 在提 高产量的同时又获得优良品质的纤维成为植棉的首
要问题。

纤维强度是衡量棉纤维品质的重要指标, 棉花 纤维强度主要取决于纤维的加厚发育, 加厚发育实 际上是纤维素不断沉积于次生壁内, 使次生壁不断 增加的过程 (单世华等, 2000a, 2000b, 2002; 刘继华 等, 1994; Gokani \& Thaker, 2002), 在这一过程中, 蔗 糖合成酶和 $\beta-1,3$-葡聚糖酶起着重要作用 (Ruany \& Chourey, 1998; Shimizu et al ., 1997)。现有研究报道, 
蔗糖合成酶在植物体内主要作为分解酶, 将库器官 中蔗糖分解为 UDPG 和果糖 (Ruany \& Chourey, 1998; Shimizu et al., 1997; Nakai et al ., 1998), 在棉花 纤维素合成中蔗糖合成酶也具有重要作用, 免疫印 迹显示庶糖合成酶在次生壁纤维素合成时达到最高 量, 而在次生壁形成停止时检测不到蔗糖合成酶的 存在( Ruany et al ., 1997)。对 $\beta-1,3$-葡聚糖酶的报 道主要集中在水稻 (Oryza sativa) 和烟草( Nicotiana) 等植物中, 当植物受到病毒和细菌等外界不良因素 刺激后在体内积累大量的病程相关蛋白(史益敏等, 1993), 以 $\beta-1$, 3-葡聚糖酶和几丁质酶等防御酶为 主。在棉花抗病性研究中, 不同品种棉花愈伤组织 对黄萎病菌毒素粗提物的抗性与体内 $\beta-1,3$-葡聚糖 酶和几丁质酶活性水平有关 (李颖章等, 2003)。

现有关于温度对棉铃发育影响的研究多是围绕 棉纤维素和干物质累积进行 (黄骏麒, 1998; 刘毓湘, 1995; 中国农业科学院棉花研究所, 1983), 认为棉花 铃期 $20{ }^{\circ} \mathrm{C}$ 以上的日均温对棉铃发育十分有利, 25 ${ }^{\circ} \mathrm{C}$ 左右的日均温是棉纤维发育的最适温度, 温度适 宜有利于棉纤维加厚发育, 加厚发育盛期的纤维素 含量高而单糖含量低, 后期低温使纤维素合成量减 少而单糖含量增高, 纤维素合成速率减慢, 棉纤维比 强度降低, 纤维加厚发育期高于 $18{ }^{\circ} \mathrm{C}$ 的日均温对棉 铃干物质累积影响较小, $15^{\circ} \mathrm{C}$ 是棉铃干物质累积的 最低温度。但迄今为止, 在棉纤维加厚发育期( 铃龄 $25 \sim 50 \mathrm{~d}$ ), 从棉纤维加厚发育的酶学变化角度来研 究棉纤维比强度形成的报道较少, 关于棉纤维加厚 发育关键酶蔗糖合成酶和 $\beta-1,3$ - 葡聚糖酶活性的变 化, 尤其低温条件下酶活性变化对次生壁纤维素累 积量与累积速率的影响, 以及最终纤维比强度形成 差异的相关报道至今没有。

本研究通过设置不同播期创造温度梯度, 研究 低温条件下棉纤维加厚过程中 (即铃龄 $25 \sim 50 \mathrm{~d}$ ) 纤 维素累积及纤维比强度形成的生理机制, 为采取调 控措施解决目前棉花生产中存在的晚熟劣质问题提 供理论依据。

\section{1 材料和方法}

\section{1 试验设计}

试验于 $2002 \sim 2003$ 年在江苏省农业科学研究 院进行, 供试土壤为马肝土, 土壤肥力中等偏上, 供 试棉花品种为 “美棉 33B”。2002 年试验设 4 个播种 期, 播期分别为 4 月 20 日、 5 月 10 日、 6 月 10 日和 6 月 22 日; 2003 年试验设 3 个播种期, 播期分别为 5
月 1 日、 5 月 20 日和 6 月 21 日。田间管理按高产栽 培要求进行。

两年试验棉花开花后分别对各播期生长一致棉 株 7 9 果枝、10 12 果枝的 1、2 果节当日白花挂牌 标记。从铃龄 $25 \mathrm{~d}$ 开始每隔 $5 \mathrm{~d}$ 取生长发育一致的 挂牌棉铃 5 8 个, 将纤维和种子分开, 纤维保存在 超低温冰箱 $\left(-30{ }^{\circ} \mathrm{C}\right)$ 备用。待挂牌标记棉铃成熟 吐絮后收获, 风干后测定铃重, 轧花后测定衣分和纤 维比强度。

试验所用气象资料由南京气象局提供, 两年棉 纤维加厚发育期的日均温见表 1 。

表 1 棉纤维加厚发育期日均温 (2002 2003)

Table 1 Mean daily temperature during cotton fiber thickening development period $(2002-2003)$

\begin{tabular}{ccc}
\hline $\begin{array}{c}\text { 播种期 } \\
\text { Planting dates }\end{array}$ & $\begin{array}{c}\text { 开花日期 } \\
\text { Blossom dates }\end{array}$ & $\begin{array}{c}\text { 日均温 }\left({ }^{\circ} \mathrm{C}\right) \\
\text { Mean daily temperature }\end{array}$ \\
\hline $2002-04-20$ & $2002-07-27$ & 26.0 \\
$2002-05-10$ & $2002-08-07$ & 24.0 \\
$2002-06-10$ & $2002-09-02$ & 21.3 \\
$2002-06-22$ & $2002-09-06$ & 19.6 \\
$2003-05-01$ & $2003-08-01$ & 26.2 \\
$2003-05-20$ & $2003-08-11$ & 24.5 \\
$2003-06-21$ & $2003-09-21$ & 15.8 \\
\hline
\end{tabular}

\section{2 测定内容与方法}

\subsection{1 测定内容}

2002 年试验主要测定棉纤维可溶性蛋白含量、 内源保护酶活性、丙二醛含量, 蔗糖合成酶活性和 $\beta-$ 1, 3-葡聚糖酶活性, 纤维干重百分率、纤维素含量和 纤维比强度; 2003 年试验主要测定棉纤维庶糖合成 酶活性和 $\beta-1,3$ - 葡聚糖酶活性, 纤维干重百分率、纤 维素含量和纤维比强度。

\subsection{2 测定方法}

内源保护酶的测定, 用考马斯亮蓝法测定可溶 性蛋白质含量, 用愈创木酚法测定过氧化物酶 (POD) 活性, 用高锰酸钾滴定法测定过氧化氢酶 (CAT) 活性, 用 Dhindsa 的方法测定丙二醛 (MDA) 含 量(李合生, 2000)。用果糖和 UDPG 比色法测定蔗 糖合成酶活性 (上海市植物生理学会, 1985), 用昆 布多糖比色法测定 $\beta-1,3$ - 葡聚糖酶活性( 中国科学 院上海植物生理研究所, 1999), $\beta-1,3$-葡聚糖酶一个 酶活力单位 $(\mathrm{U})$ 定义为每秒从还原昆布多糖中释放 出 $1 \mathrm{nmol}$ 葡萄糖所需的酶量, 酶活性以每克鲜样重 的酶活力单位表示。

用瑞典 Tecator 纤维系列仪测定棉花纤维素含 
量。

用德国 BRUKER 公司 D8 DISCOVER with GADDS X 射线衍射仪收取棉纤维 002 衍射峰在方位 角方向的强度数据, 并扣除杂散散射。用半高宽之 半表征晶区在棉纤维中总取向参数 $(\psi)$ 。联立方程 组: $0.5 \times e^{\ln 2 \times\left(\frac{w_{1}}{\alpha}\right)^{2}}=\cos \left(\mathrm{h} \times 2 \ln 2 \times\left(\frac{w_{1} \times \psi}{\alpha}\right)^{2}\right)\left(w_{1}\right.$ 为实验曲线 $50 \%$ 高度之半宽角度) 和 $0.4 \times$ $e^{\ln 2 \times\left(\frac{w_{2}}{\alpha}\right)^{2}}=\cos \left(\mathrm{h} \times 2 \ln 2 \times\left(\frac{w_{2} \times \psi}{\alpha}\right)^{2}\right)\left(w_{2}\right.$ 为实验曲 线 $40 \%$ 高度之半宽角度), 求解出螺旋角 $(\varphi)$ 和取向 分散角 $(\alpha)$ 。

纤维比强度的测定是混匀纤维样品后用棉花纤 维引伸器制成棉条, 用国产 $\mathrm{Y} 162 \mathrm{~A}$ 型束纤维强力机 测定 $3.2 \mathrm{~mm}$ 隔距比强度,测 6 次重复平均值作为试 样代表值, 并用中国纤维检验局的标准棉样修正。

\section{2 结果与分析}

\section{1 低温对棉纤维可溶性蛋白含量的影响}

从图 1 看出, 棉纤维可溶性蛋白含量随着铃龄 的增加表现为先上升后下降, 为一单峰曲线, 不同处 理随纤维加厚发育期温度的降低而升高。26.0 和 $24.0{ }^{\circ} \mathrm{C}$ 是棉纤维发育的适宜温度, 可溶性蛋白含量 最大值出现在铃龄 $35 \mathrm{~d}$, 温度降低峰值延后, 温度降 低到 21.3 和 $19.6{ }^{\circ} \mathrm{C}$ 时, 峰值推迟到铃龄 $45 \mathrm{~d}$ 。

2.2 低温对棉纤维内源保护酶活性的影响

\subsubsection{CAT 活性}

图 1 棉纤维可溶性蛋白含量的动态变化 (2002)

Fig. 1 Dynamic changes of the soluble protein content in cotton fiber (2002)

$-26.0{ }^{\circ} \mathrm{C} 、 \cdots \bigcirc \cdots 24.0{ }^{\circ} \mathrm{C} 、-\nabla-21.3{ }^{\circ} \mathrm{C} 、 \cdots \triangle \cdots 19.6{ }^{\circ} \mathrm{C}$ : 分别 表示 4 个播期铃龄 $25 \sim 50 \mathrm{~d}$ 日均温. Stand for mean daily temperature within boll age of 25 to 50 days for different four planting dates respectively
从图 2A 看出, 棉纤维 CAT 活性随铃龄增加表 现为先上升后下降的变化趋势, 不同处理随纤维加 厚发育期温度的降低而降低。当温度为 26.0 和 $24.0{ }^{\circ} \mathrm{C}$ 时, CAT 活性差异较小, 最大值出现在铃龄 $35 \mathrm{~d}$; 温度降到 21.3 和 $19.6{ }^{\circ} \mathrm{C}$ 时, CAT 活性明显降 低, 活性最大值也在铃龄 $35 \mathrm{~d} 。 26.0$ 和 $24.0{ }^{\circ} \mathrm{C}$ 两个 正常温度处理的 CAT 活性显著高于 21.3 和 $19.6{ }^{\circ} \mathrm{C}$ 两个低温处理,正常温度与低温间差异明显大于正 常温度 $\left(26.0\right.$ 与 $24.0{ }^{\circ} \mathrm{C}$ ) 之间、低温 (21.3 与 19.6 $\left.{ }^{\circ} \mathrm{C}\right)$ 之间的差异。

\subsubsection{POD 活性}

从图 2B 看出, 在 26.0 和 $24.0{ }^{\circ} \mathrm{C}$ 的温度条件 下, 棉纤维 POD活性随铃龄增加而下降,下降幅度 
较大, 到铃龄 $50 \mathrm{~d}$ 时降至最低, 两个正常温度处理 间差异较大; 当温度降到 21.3 和 $19.6{ }^{\circ} \mathrm{C}$ 时, POD 活 性随铃龄延后变化平缓, 两个低温处理间差异较小, 但显著低于正常温度条件下的 POD 值。

\section{3 低温对棉纤维 MDA 含量的影响}

从图 3 看出, 在 26.0 和 $24.0{ }^{\circ} \mathrm{C}$ 的正常温度条 件下, 棉纤维 MDA 含量随着铃龄的增加呈持续下降 趋势, 不同处理间差异显著。当温度降到 21.3 和 $19.6{ }^{\circ} \mathrm{C}$ 时, $\mathrm{MDA}$ 含量随着铃龄的增加呈持续上升趋 势, 处理间差异也显著, 铃龄 $25 \sim 35 \mathrm{~d}$ 低于正常温 度时的 MDA 含量, 但从铃龄 $40 \mathrm{~d}$ 开始 MDA 累积速 率加快, 在铃龄 $50 \mathrm{~d}$ 时超过正常温度处理的 MDA 含量。说明温度降低到 $21.3{ }^{\circ} \mathrm{C}$ 时, 棉纤维在加厚发 育过程中植物组织的保护能力逐渐降低, 到 $19.6{ }^{\circ} \mathrm{C}$ 时更明显。

\section{둘}

图 3 棉纤维 MDA 含量的动态变化 (2002)

Fig.3 Dynamic changes of the malondiadehycle content in cotton fiber (2002)

图例同图 1 Legends see Fig. 1

2.4 低温对棉纤维加厚发育期蔗糖合成酶和 $\beta$ 1,3-葡聚糖酶活性的影响

2.4.1 蔗糖合成酶活性

在棉纤维细胞发育过程中, 庶糖合成酶作为分 解酶将运转到棉铃的蔗糖分解为 UDPG 和果糖, UDPG 进一步合成纤维素 (Carpita \& Delmer, 1981), 是一种对棉纤维加厚发育起到重要作用的酶。从图 4A、B 可以看出, 两年试验结果表明, 棉纤维熫糖合 成酶活性随着铃龄的增加呈单峰曲线变化趋势, 在 铃龄 $40 \mathrm{~d}$ 左右达到峰值, 不同处理随纤维加厚发育 期温度的降低而降低。在 26.0 和 $24.0{ }^{\circ} \mathrm{C}$ 的正常温
度条件下, 蔗糖合成酶活性处理间差异明显, 但处理 间的差异年际间有异。2002 年当温度降到 21.3 和 $19.6{ }^{\circ} \mathrm{C}$ 时, 处理间差异较小, 蔗糖合成酶活性较正 常温度处理显著下降, 2003 年试验当温度为 $15.8{ }^{\circ} \mathrm{C}$ 时, 蔗糖合成酶活性表现最低。

\subsection{2 $\beta-1$, 3-葡聚糖酶活性}

研究表明, $\beta-1,3$-葡聚糖酶和 $\beta-1,4$-葡聚糖酶与 胼胝质和纤维素的生物合成密切相关 (Amor et al., 1995; Ellis et al., 1997), 从图 4C、D 看出, 棉纤维 $\beta-$ 1, 3-葡聚糖酶活性随铃龄的增加总体呈下降趋势, 不同处理随纤维加厚发育期温度的降低而升高。在 26.0 和 $24.0{ }^{\circ} \mathrm{C}$ 的正常温度条件下, $\beta-1$, 3-葡聚糖酶 活性处理间差异在 2002 年明显, 但 2003 年差异较 小。2002 年当温度降到 21.3 和 $19.6{ }^{\circ} \mathrm{C}$ 时, 处理间 差异较小, 但仍高于正常温度处理。2003 年试验当 温度降到 $15.8{ }^{\circ} \mathrm{C}$ 时, $\beta-1,3$-葡聚糖酶活性显著高于 正常温度处理。

\section{5 低温对纤维干重和纤维素含量的影响}

\subsection{1 纤维干重百分率}

从图 5A、B 看出, 纤维干重百分率随着铃龄的 增加呈上升趋势, 不同处理随纤维加厚发育期温度 的降低而降低。在 26.0 和 $24.0{ }^{\circ} \mathrm{C}$ 的正常温度条件 下,纤维干重百分率处理间差异在 2002 年明显, 在 2003 年较小, 但均显著高于低温处理。2002 年当温 度降到 21.3 和 $19.6{ }^{\circ} \mathrm{C}$ 时, 处理间差异较小, 2003 年 在 $15.8{ }^{\circ} \mathrm{C}$ 的温度条件下, 纤维干重百分率显著降 低。

\section{5 .2 纤维素含量}

研究表明, 铃龄 $25 \sim 50 \mathrm{~d}$ 棉纤维细胞伸长减 弱, 从纤维伸长期过渡到纤维加厚发育期, 即纤维素 合成并沉积于纤维次生壁内侧使次生壁加厚的时期 (Schuber \& Benedict, 1973)。从图 5 看出, 纤维素含 量随着铃龄的增加呈上升趋势, 不同处理随纤维加 厚发育期温度的降低而降低。在正常温度条件下， 纤维素含量处理间差异虽然在 2002 年较明显, 在 2003 年差异较小, 但两年均以铃龄 $25 \sim 35 \mathrm{~d}$ 之间的 纤维素累积速率较大。2002 年当温度降到 21.3 和 $19.6{ }^{\circ} \mathrm{C}$ 时, 纤维素含量处理间差异较小, 含量较正 常温度处理显著下降; 2003 年当温度降到接近棉铃 干物质停止累积的温度时 $\left(15{ }^{\circ} \mathrm{C}\right)$, 纤维素的累积速 率和累积量显著下降, 在铃龄 $35 \sim 50 \mathrm{~d}$ 纤维素累积 速率快速增加, 但纤维素总量明显降低, 仅为正常温 度的一半, 说明低温不仅影响纤维素的累计量而且 影响纤维素的累积速率, 而高强纤维的形成是以 
图 4 棉纤维蔗糖合成酶活性 $(\mathrm{A}, \mathrm{B})$ 和 $\beta-1,3$-葡聚糖酶活性 $(\mathrm{C}, \mathrm{D})$ 的动态变化

Fig.4 Dynamic changes of the sucrose synthase activity (A, B) and $\beta-1,3$-glucanase activity ( C, D) in cotton fiber

- $26.2{ }^{\circ} \mathrm{C} 、 \cdots \nabla \cdots 24.5{ }^{\circ} \mathrm{C} 、 \cdots+\cdots 15.8{ }^{\circ} \mathrm{C}$ : 分别表示 2003 年 3 个播期铃龄 $25 \sim 50 \mathrm{~d}$ 日均温 Stand for mean daily temperature within boll age of 25 to 50 days for different three planting dates respectively in 2003

纤维素的平稳沉积为基础的。

2.6 低温对铃重和衣分的影响

2.6.1 铃重

从图 6A 看出, 棉花铃重随铃龄 $25 \sim 50 \mathrm{~d}$ 内温 度的降低呈下降趋势, 虽然年际间棉花铃重差异较 大, 但在 26.0 和 $24.0{ }^{\circ} \mathrm{C}$ 的正常温度条件下的铃重 处理差异均较小, 2002 年当温度降低到 $19.6{ }^{\circ} \mathrm{C}$ 时铃 重为 $4.63 \mathrm{~g}, 2003$ 当温度降低到 $15.8{ }^{\circ} \mathrm{C}$ 时铃重仅为 $3.22 \mathrm{~g}$, 均较正常温度处理下降 $10 \%$ 以上。

2.6.2 衣分

从图 6B 看出, 衣分随铃龄 $25 \sim 50 \mathrm{~d}$ 内温度的
降低呈下降趋势, 年际间差异较大。在正常温度条 件下, 衣分处理差异均较小; 温度降低衣分下降, 2002 年当温度降低到 $19.6{ }^{\circ} \mathrm{C}$ 时衣分为 $34.87 \%$, 均 较正常温度处理下降 $9 \%$ 左右, 2003 当温度降低到 $15.8{ }^{\circ} \mathrm{C}$ 时衣分为 $33.52 \%$, 较正常温度处理下降幅 度在 $5 \%$ 以内。

\section{7 低温对纤维超分子结构取向参数的影响}

2.7 .1 取向分散角 $(\alpha)$

取向分散角表征的是棉纤维次生壁螺旋结构 中,纤维素大分子聚合而成的晶粒在螺旋结构中的 取向, 即微原纤取向和基原纤取向的夹角 (刘继华 
等, 1996）。从图 7A 看出,2002 年分散角随铃龄 25 $\sim 50 \mathrm{~d}$ 内温度的降低表现为先上升后下降的趋势, 当温度降低到 $21.3{ }^{\circ} \mathrm{C}$ 时分散角最大, 不利于高强纤 维的形成, 2003 年分散角随铃龄 $25 \sim 50 \mathrm{~d}$ 内温度的 降低表现为不断宽化的趋势, 说明低温影响了棉纤 维超分子结构的优化。

\subsection{2 螺旋角 $(\varphi)$}

螺旋角表征的是基原纤螺旋排列方向与纤维纵 轴的夹角(刘继华等, 1996)。从图 7B 看出, 2002 年 螺旋角随铃龄 $25 \sim 50 \mathrm{~d}$ 内温度的降低表现为先上 升后下降的趋势, 当温度降低到 $21.3{ }^{\circ} \mathrm{C}$ 时分散角最 大, 不利于高强纤维的形成, 2003 年分散角随铃龄
$25 \sim 50 \mathrm{~d}$ 内温度的降低表现为不断宽化的趋势。

\section{7 .3 取向分布角 $(\psi)$}

取向分布角表征的是棉纤维超分子结构总取 向, 一般 $\psi$ 角值愈小, 纤维素大分子有序程度愈高, 纤维强度愈高(刘继华等, 1996)。从图 7C 看出, 2002 年分布角随铃龄 $25 \sim 50 \mathrm{~d}$ 内温度的降低表现 为先上升后下降的趋势, 当温度降低到 $21.3{ }^{\circ} \mathrm{C}$ 时分 散角最大, 不利于高强纤维的形成, 2003 年分散角 随铃龄 $25 \sim 50 \mathrm{~d}$ 内温度的降低表现为不断宽化的 趋势。

\section{8 低温对纤维比强度的影响}

纤维比强度是衡量棉纤维拉伸特性的主要指 
图 6 不同温度条件下棉花铃重和衣分的差异（2002～2003）

Fig. 6 Difference of boll weight and lint percent of cotton in different temperature conditions $(2002-2003)$

$\square: 2002$ 年 4 个播期数据 Data of four seedtimes in $2002 \quad \square: 2003$ 年 3 个播期数据 Data of three seedtimes in 2003

标, 并与棉纤维的成纱品质密切相关, 其中 $3.2 \mathrm{~mm}$ 隔距比强度与纺纱关系较大 (刘继华和尹承佾, 1991; 单世华等, 2002)。从图 8 看出,纤维比强度随 着铃龄 $25 \sim 50 \mathrm{~d}$ 内温度的降低呈单峰曲线变化趋 势。在正常温度条件下,两年均在 $24{ }^{\circ} \mathrm{C}$ 左右的温度 条件下纤维比强度最大, 2002 年为 $24.86 \mathrm{cN} \cdot \mathrm{tex}^{-1}$, 2003 年为 $24.64 \mathrm{cN} \cdot \mathrm{tex}^{-1}$, 温度升高或降低纤维比 强度均降低, 但以低温对纤维比强度的影响作用大。 2002 年当温度降到 $19.6{ }^{\circ} \mathrm{C}$ 时, 纤维比强度仅为 $20.38 \mathrm{cN} \cdot \mathrm{tex}^{-1}$, 比最高值降低 $18.02 \%$, 差异明显; 2003 年温度降低到 $15.8{ }^{\circ} \mathrm{C}$ 时, 纤维比强度仅为 $15.73 \mathrm{cN} \cdot$ tex $^{-1}$ 。

图 7 不同温度条件下棉纤维取向分散角 (A)、螺旋角 (B) 和取向分布角 $(\mathrm{C})$ 的差异 (2002 2003)

Fig.7 Difference of fiber orientational separate angle (A), spiral angle (B) and orientational distribution angle (C) of cotton in different temperature conditions $(2002-2003)$

图例见图 6 Legends see Fig. 6 
图 8 不同温度条件下棉花纤维比强度的差异（2002～2003）

Fig. 8 Difference of fiber strength of cotton in different temperature conditions $(2002-2003)$

图例见图 6 Legends see Fig. 6

\section{3 讨 论}

许萱和许玉璋 (1989)研究发现, $20{ }^{\circ} \mathrm{C}$ 以上的平 均温度对棉铃发育十分有利, 刘振英等(1988) 则认 为铃重与铃龄 $50 \mathrm{~d}$ 平均温度呈对数关系, 温度高于 $21{ }^{\circ} \mathrm{C}$ 时铃重增加缓慢, 低于 $21{ }^{\circ} \mathrm{C}$ 时铃重明显随温 度下降而减轻。前人大多只局限于铃重、衣分、棉铃 体积等最终结果的研究 (刘毓湘, 1995; 张金帮, 2000; 陈德华, 2001), 从现象 (温度)到结果 (铃重), 没有探讨造成这种结果的内在机制。本试验进一步 研究了棉纤维加厚发育期即铃龄 $25 \sim 50 \mathrm{~d}$ 的相关 生理指标的变化规律, 从内在生理变化说明了温度 尤其低温对棉纤维加厚发育以及纤维比强度形成的 影响。研究结果表明: 铃龄 $25 \sim 50 \mathrm{~d}$ 日均温在 24.0 ${ }^{\circ} \mathrm{C}$ 左右时, 是形成高强棉纤维的适宜温度, 在该温度 条件下蔗糖合成酶活性高, $\beta-1,3$ - 葡聚糖酶活性低, 纤维素的累积量和累积速率均明显高于其它温度, 超分子取向参数角不断优化,有利于高结晶、高取向 纤维结构的建成, 最终纤维比强度显著高于其它温 度; 当温度上升到 $27.0{ }^{\circ} \mathrm{C}$ 左右时的棉纤维比强度较 $24.0{ }^{\circ} \mathrm{C}$ 时不升反降, 说明纤维比强度的形成应存在 一个适宜温度, 并不是随着温度的上升而无限增加 的, 至于 $27.0{ }^{\circ} \mathrm{C}$ 是否是上限温度还须进一步研究; 当温度下降到 $21.0^{\circ} \mathrm{C}$ 左右时, 蔗糖合成酶活性开始 降低, $\beta-1,3$ - 葡聚糖酶活性开始升高, 说明该温度是 棉纤维加厚发育关键酶活性发生转变的临界温度,
表现为纤维比强度也开始显著降低; 当温度降到 $15.0{ }^{\circ} \mathrm{C}$ 左右时, 蔗糖合成酶活性也显著降低, $\beta-1,3-$ 葡聚糖酶活性也显著升高, 纤维超分子结构取向参 数角明显宽化, 棉纤维已经不能正常发育, 铃重仅为 $3.22 \mathrm{~g}$, 纤维比强度仅为 $15.73 \mathrm{cN} \cdot \mathrm{tex}^{-1}$, 说明该温 度条件下棉纤维强度的建成已趋于停止。这与刘继 华关于纤维强度与温度呈正比关系、以全铃期 $18{ }^{\circ} \mathrm{C}$ 为转折点 (低于 $18{ }^{\circ} \mathrm{C}$ 影响较大, 高于 $18{ }^{\circ} \mathrm{C}$ 影响较 小)的研究结果不符。

当纤维加厚发育期温度低于 $21.3{ }^{\circ} \mathrm{C}$ 时, 棉纤维 可溶性蛋白含量增加, 可能是低温逆境, 细胞产生大 量抗逆性蛋白, 棉纤维内源保护酶活性降低, 纤维细 胞受伤害程度加强, 细胞活力水平降低, 代谢不旺 盛, 同时细胞衰老加快, 从而减慢了纤维细胞的增厚 发育。其中 POD 活性的变化趋势与单世华研究结 果相同, 即随温度降低 POD 活性降低, 高峰出现时 间推迟。

本研究首次揭示了低温条件下蔗糖合成酶和 $\beta$ 1,3-葡聚糖酶在棉纤维加厚发育过程中的动态变化 规律。结果表明, 纤维加厚发育期温度低于 $21.3{ }^{\circ} \mathrm{C}$ 时, 蔗糖合成酶活性及变化幅度降低, 由于蔗糖合成 酶提供合成纤维素或胼胝质的前体物质 UDPG, 说 明在此温度条件下已减少了 UDPG 的形成和供应速 度, $\beta-1,3$ - 葡聚糖酶活性上升且温度越低活性越高, 说明低温条件下在棉纤维加厚发育期 $\beta-1,3$-葡聚糖 酶利用 UDPG 大量合成胼胝质, 减少了纤维素的沉 积, 使纤维超分子结构取向参数角加大, 最终导致纤 维比强度降低。

棉纤维比强度取决于纤维加厚发育形成的次生 壁特性, 低温影响纤维比强度的形成是通过影响纤 维加厚发育过程实现的。棉纤维加厚发育是一个极 其复杂的生理生化过程, 不仅与上述酶有关, 还受 $\beta-$ 1,4-葡聚糖酶以及 Expansin 等影响, 而且棉株中生 长调节物质也起着重要作用, 因此进一步深入研究 应从以下两方面展开: 一是展开低温条件下 $\beta-1,4-$ 葡聚糖酶的研究, $\beta-1,4$ - 葡聚糖酶是利用蔗糖合成酶 提供的前体物质 UDPG 合成纤维素, 明确是否与 $\beta-$ 1,3 -葡聚糖酶存在反向调控, 竞争同一底物 (UDPG); 其次研究各种生长调节物质在棉纤维加厚 发育过程中的动态变化规律, 以及外源调节物质对 加厚过程的影响。

\section{参 考 文 献}

Amor Y, Haigler CH, Johnson S (1995). Amembrane associated 
form of sucrose synthase and its potential role in synthesis of cellulose and callose in plant. Proceedings of National Academic Science USA, 9, 9353 - 9357.

Carpita NC, Delmer DP ( 1981 ). Concentration and metabolic turnover of UDP-Glucose in developing cotton fibers. Journal of Biological Chemistry, 25, $308-315$.

Chen DH (陈德华), Zhou GS (周桂生), Chen Y (陈源), Wu YK (吴六康) (2001). Study of cotton bous add weight ways of high production cotton plant. Jiangxi Cottons (江西棉花), 23 (3), $18-22$. (in Chinese with English abstract)

Cotton Research Institute of Chinese Academy of Agricultural Sciences (中国农业科学院棉花研究所) (1983). China Cotton Cultivation Science (中国棉花栽培学). Shanghai Scientific and Technical Publishers, Shanghai. (in Chinese)

Ellis RP, Swanston JS, Rubiot A (1997). The development of $\beta$ glucanase and degradation of $\beta$-glucan in barley grown in scotland and spain. Journal of Cereal Science, 26, 75-82 .

Gokani SJ, Thaker VS (2002). Physiological and biochemical changes associated with cotton fiber development. IX. Role of IAA and PAA. Field Crops Research, 77, 127-136.

Huang JQ (黄骏麒) (1998)。China Cotton Farming (中国棉作 学). China Agricultural Science and Technology Press, Beijing. (in Chinese)

Li HS (李合生) (2000). Principles and Techniques of Plant Physiological Biochemical Experiment (植物生理生化实验原理和 技术). Higher Education Press, Beijing. (in Chinese)

Li YZ (李颖章), Zheng XH (郑晓华), Tang HL (唐海林), Zhu JW (朱建伟), Yang JM (杨晶明) (2003). Increase of $\beta$ 1,3 - glucanase and chitinase activities in cotton callus cells treated by salicylic acid and toxin of Verticillium dahiae. Acta Botanica Sinica (植物学报), 45, 802 - 808. (in English with Chinese abstract)

Liu JH (刘继华), Yin CY (尹承佾) (1991). Cotton fiber cellulose accumulation and form of fiber strength. Acta Agriculturae Uncleatae Sinica (核农学报), 6, 205-209. (in Chinese)

Liu JH (刘继华), Yin CY (尹承佾), Yu FY (于凤英), Sun QR (孙清荣), Wang YM (王永民), Jia JN (贾景农), Bian DC (边栋材), Chen XL (陈学留) (1994). Formation mechanism and improvement approach of cotton fiber strength. Scientia Agricultura Sinica（中国农业科学)，27（5), 10 - 16.（in Chinese with Engilsh abstract)

Liu JH (刘继华)，Yin CY (尹承佮)，Yu FY (于凤英), Liu YX (刘英欣) (1996). Effects of anthesis date on the dynamic change of cotton fiber super-molecular structure and strength. Scientia Agricultura Sinica (中国农业科学), 29(1), 59-65. (in Chinese with English abstract)

Liu YX (刘毓湘) (1995). Contemporary World Cotton (当代世 界棉业). China Agriculture Press, Beijing. (in Chinese)

Liu ZY (刘振英), Wang SY (王寿元), Dong RL (董人伦), Mao CX (毛朝兴) (1988). The relations between Summer cotton boll developing rule and the environment. China Cotton (中 国棉花), 15(3), 29-32. (in Chinese)

Nakai T, Tonouchi N, Konishi T (1998). Evidence for the critical role of sucrose synthase for anoxic tolerance of maize roots using a double mutant. Proceedings of National Academic Science USA, 96, $14-18$.

Ruany L, Chourey PS (1998) . A fiberless seed mutation in cotton is associated with lack of fiber cell initiation in ovule epidermis and alteration in sucrose synthase expression and carbon partitioning in developing seeds. Plant Physiology, 11, $399-406$.

Ruany L, Prem S, Deborah P, Luis P (1997). The differential expression of sucrose synthase in relation to diverse patterns of carbon partitioning in developing cotton seed. Plant Physiology, $11,375-385$.

Schuber AM, Benedict CR (1973) . Cotton fiber development kinetics of cell elongation and secondary wall thickening. Crop Science, 13, $704-709$.

Shan SH (单世华), Sun XZ (孙学振), Zhou ZG (周治国), Shi $\mathrm{P}$ (施培), Bian DC (边栋材) (2000a). Effect of temperature on cotton fiber strength and super-molecular structure. Acta Agronomic Snica（作物学报)，26，667-672. (in Chinese with English abstract)

Shan SH (单世华), Sun XZ (孙学振), Zhou ZG (周治国), Shi $\mathrm{P}$ (施培) (2000b). Effect of temperature on fiber quality of cotton. Acta Agriculture Boreali-Sinica (华北农学报), 15 (4), 120 - 125. (in Chinese with English abstract)

Shan SH (单世华), Sun XZ (孙学振), Zhou ZG (周治国), Shi P (施培), Bian DC (边栋材) (2002). Effect of anthensis date and fruiting branches on cotton fiber strength and super-molecular structure. Scientia Agricultura Sinica (中国农业科学), 35, 163 - 168. (in Chinese with English abstract)

Shanghai Institute of Plant Physiology of Chinese Academy of Sciences (中国科学院上海植物生理研究所) (1999). Contemporary Plant Physiological Experiment Manual (现代植物生理 学实验指南). Science Press, Beijing. (in Chinese)

Shi YX (史益敏), Yan JQ (颜季琼), Fei XN (费雪南), Xu YQ (许煜泉) (1993). Purification and character of $\beta-1,3-$ glucanase from tomato infected tobacco mosaic virus. Journal of Plant Physiology (植物生理学报), 19, 333 - 338. (in Chinese with English abstract)

Shimizu Y, Aotsuka S, Hasegawa O, kawada T, Sakuno T, Sakai F, Hayashi T (1997). Changes in levels of mRNA for cell wellrelated enzymes in growing cotton fiber cells. Plant and Cell Physiology, 38, $375-378$.

The Shanghai Society for Plant Physiology (上海市植物生理学 会) (1985). Plant Physiological Experiment Manual (植物生 理学实验手册). Shanghai Scientific and Technical Publishers, Shanghai. (in Chinese)

Xu X (许萱)，Xu YZ (许玉璋) (1989). Effect of environmental factors on growth and development of cotton. III . Relationship between cotton procreation growth and temperature. Jiangxi Cottons (江西棉花), 11(2), 4-13. (in Chinese)

Zhang JB (张金帮), Wang Y (王勇), Mao YF (毛允峰) (2000). Effect of meteorologic factor on cotton weight and lint percent. Jiangxi Cottons (江西棉花), 22(2), 29 - 32. (in Chinese) 